katsottiin myös Idäntutkimuksen valteiksi. Lisäksi Idäntutkimuksen rooli nuorten tutkijoiden julkaisutoiminnan ja uran edistämisessä voidaan nähdä erityisen tärkeäksi. Esimerkiksi Pro gradu -palkinnon saaja voi julkaista opinnäytteeseensä pohjautuvan artikkelin lehdessä.

VIETS palkitsee vuosittaiseen kilpailuun ilmoitetut edeltävän vuoden parhaat Venäjää ja Itä-Eurooppaa käsittelevät pro gradu -tutkielmat. Tänä vuonna kilpailun voitti Lisa Gohlke. Hänen yhteiskuntamaantieteen alaan kuuluva tutkielmansa "People Believe in What They Want to Believe: Myriad Ways to Embed the RomanianMoldovan State Border in Collective Identities in Everyday Life" valmistui Itä-Suomen yliopiston kansainvälisestä Border Crossings -maisteriohjelmasta. Työ käsittelee kollektiivisia identiteet- tejä ja arkea yhdellä kiinnostavalla, mutta varsin vähän tutkitulla Romanian ja Moldovan rajaalueella Kaakkois-Euroopassa. Kilpailun toisen palkinnon sai Jarkko Hietala. Hänen tutkielmansa "Kuoleman laaksossa: prosessijäljitysanalyysi julkisen sitoumuksen vaikutuksesta Krimin sodan diplomatiassa" valmistui Tampereen yliopiston Johtamiskorkeakoulun politiikan tutkimuksen tutkinto-ohjelmasta. Hietala tarkastelee työssään 1800-luvun turvallisuusjärjestelmän muutosta ja suurvaltojen välisiä suhteita Krimin sodan esimerkin kautta. Onnittelut vielä kerran palkituille! Seminaarin päätteeksi nostimme maljan 30-vuotiaalle seuralle.

Olga Hannonen \& Minna Piipponen

\title{
Akateemisena vanhempana BASEES-konferenssissa 12.-14.4.2019
}

Berliinin muurin murtumisesta tulee marraskuussa kuluneeksi kolmekymmentä vuotta. Muurin murtuminen ja kommunismin kaatuminen olivat tänä vuonna Britannian Slaavilaisen ja ItäEuroopan tutkimuksen yhdistyksen (British Association of Slavonic and East-European Studies, BASEES) järjestämän konferenssin pääteema. Myös Baseesissa puhalsi pienimuotoinen wind of change, mikäli konferenssia tarkastelee tieteidenvälisestä ja perhepoliittisesta näkökulmasta.

Sain helmikuussa 2019 kutsun Baseesin monivuotiselta presidentiltä, Oxfordin yliopiston emeritaprofessori Judith Pallot'lta pitää puheenvuoron neuvostoliittolaisten muusikkojen reaktioista Berliinin muurin murtumiseen konferenssin pääpaneelissa avajaispäivänä 12.4.2019. Sanoin heti, etten matkusta ilman vuoden ikäistä poikaani. Cambridgessa vuosittain järjestettävää konferenssia on kritisoitu siitä, ettei se ota huomioon perheellisiä. Lapsilla ei ole tähän mennessä ollut lupa yöpyä järjestävän collegen kampusalueella. Basees teki kuitenkin yllättäen uuden linjauksen ja lapsestani tuli konferenssin pioneeri ja koehenkilö. Miksi? Pahat kielet sanoisivat, että Brexit tekee epätoivoiseksi, mutta todellinen syy on varmaankin sangen käytännöllinen.

Basees kykenee uudistumaan juuri nyt, koska konferenssin pitopaikka on vaihtunut. Konferenssi järjestettiin aiempina vuosina Fitzwilliam Collegessa, jonka säännöt kielsivät lasten yöpymisen kampuksella. Britanniassa monissa yliopistoissa on samanlaiset käytännöt. Kyse on useimmiten puutteellisista vakuutuksista ja siitä, ettei kampuksia ole suunniteltu lasten käyttöön. Säännöt tuottavat kuitenkin ongelmia akateemista uraa tekeville perheellisille ja professori Pallot pahoitteli, että käytäntöjä parannetaan Baseesin osalta vasta nyt. Robinson College, jossa Basees kokoontui nyt ensimmäisen kerran, on huomattavasti lapsiystävällisempi ja varastossa on jopa vauvan retkisänkyjä (Akateemisen vanhemman kannattaa kuitenkin varautua siihen, että lapsi saattaa tästä huolimatta valita juuri sinun sänkysi).

Entä minkälaista on matkustella työasioissa yksin pienen lapsen kanssa? Matkaa taitettiin lapsi rintarepussa, takana oli pelkästään huonosti nukuttuja öitä ja päiväkodista oli tarttunut ärhäkkä flunssa. Olisiko kannattanut kieltäytyä konferenssin pääpuheenvuorosta? Osallistumiseeni konferenssiin vaikutti suuressa määrin halu tuoda oman oppiaineeni ja erityisalani näkökulma esille suurelle monitieteiselle yleisölle, kun siihen kerrankin tarjoutui kunnon mahdollisuus. Monitieteisten konferenssien ongelmana on edelleen akateeminen lokeroituminen. Yhteiskuntatieteilijät tulevat harvemmin kuuntelemaan taiteentutkimuksen paneeleja. Etenkin musiikintutkimusta pidetään edelleen liian haastavana erityisalueena. Syy on myös osittain musiikkitieteilijöissä, joiden on opeteltava puhumaan musiikista ymmärrettävästi monitieteisellä areenalla. Pääpuheenvuorojen kohdalla muiden tieteenalojen edustajat eivät voi 
vedota kuitenkaan mielenkiintoisten paneelien pälllekkäisyyteen. Kutsuvieraspuheenvuoro tarjosi minulle oivan tilaisuuden pyrkiä osoittamaan täydelle salilliselle kuulijoita, mitä annettavaa musiikin tutkimuksella on monitieteiselle Venäjän ja Itä-Euroopan tutkimukselle.

Baseesin kutsuvieraana olin lapsen kanssa poikkeusasemassa. Matka Heathrow'n lentokentältä Cambridgeen taittui mukavasti taksilla ja konferenssi maksoi kaikki matkakuluni. Tavalliselle lapsen kanssa matkustavalle konferenssiosallistujalle suurin kysymys tulee olemaan taloudellinen, puhumattakaan matkan fyysisestä osuudesta, etenkin mikäli lapsi ei osaa vielä kävellä. Vaikka matka ja majoitus eivät tule kalliimmaksi alle kaksivuotiaan lapsen kanssa, ei konferenssiin voi osallistua ilman lastenhoitomahdollisuutta. Basees ei sellaista tarjoa lainkaan, sillä järjestäjillä ei ole tarkoitukseen sopivaa ammattihenkilökuntaa, jolla olisi tarvittava vakuutus. Tajutessani tämän, pyysin kahden pojan isää, historioitsijaystävääni ja Basees-konkaria kärryttelemään lapseni kanssa avajaispaneelini ajan. Lapseni oli varmoissa käsissä ja järjestäjäkin kai huokaisi helpotuksesta, sillä ehdotettiin myös, että voisin puhua lapsi sylissäni. Pallot'n mukaan Basees ei kykene tarjoamaan lastenhoitomahdollisuutta tulevaisuudessakaan, mutta johtoryhmä on päättänyt myöntää lapsen kanssa osallistuville konferenssipuhujille ensi vuonna 50 punnan stipendin lastenhoitokustannuksiin.

\section{Taiteet ja filosofia ensi kertaa Baseesin parrasvaloissa}

Kulunut konferenssi oli professori Pallot'n viimeinen ja samalla juuri valitun Baseesin uuden presidentin Matthias Neumannin ensimmäinen. Tämä näkyi jonkinlaisena riskinottona. Pääpaneelit oli rakennettu spontaaninoloisesti, käytännönläheisesti ja potentiaalisen mielenkiintoisesti. Lisäksi lapsiystävällinen politiikka ei ollut ainoa historiallinen tapahtuma Baseesissa. Ensimmäistä kertaa konferenssin historiassa Baseesin avajaispaneeli koostui taiteen ja filosofian tutkijoista. Serbialainen musiikkitieteilijäkollegani hehkutti sosiaalisessa mediassa heti puheeni jälkeen: "Jee - tänä vuonna musiikkitieteilijä on yksi Baseesin vuosittaisen konferenssin pääpuhujista! (Yleensä meitä ei huomioida lainkaan)...” Kanssani esitelmöivät Leipzigin yliopiston Leibnizhistorian ja kulttuuri-instituutin vanhempi tutkija taidehistorioitsija Beáta Hoch, J. E. Purkyně yliopiston ja Itä-Bohemian yliopiston filosofian lehtori Josef Moural ja Cambridgen yliopiston
Venäjän kirjallisuuden lehtori Josephine von Zitzewitz. Omassa puheenvuorossani kritisoin kuitenkin paneelikeskustelumme tavanomaista kysymyksenasettelua. "Taiteiden ja filosofian rooli kommunismin kaatumisessa" -otsikossa kaikuu edelleen kylmän sodan perintö. On aika lähestyä Venäjän neuvostohistoriaa uusista näkökulmista. Taiteen- ja kulttuurintutkimuksella on potentiaalia haastaa perinteinen poliittisen historian kerronta, näkemys neuvostoliittolaisesta kulttuurista erityisenä periodina Venäjän historiassa ja sen irrallisuus eurooppalaisesta aatehistoriasta. Tämä kävi ilmi enemmän tai vähemmän jokaisesta paneeliesitelmästä ja siksi on harmi, että aikataulussa ei ollut varattu lainkaan aikaa yleisökysymyksille saati panelistien väliselle keskustelulle.

Konferenssin kohutuin pääpuhuja oli entinen JUKOSin johtaja ja monimiljardööri Mihail Hodorkovski, joka tunnetaan paitsi Venäjällä kansalaisyhteiskuntaa rakentaneen ja tukeneen "Open Russia” -liikkeen perustajana, etenkin neljäntoista vuoden vankilatuomiostaan hänen kritisoituaan korruptiota vuonna 2003. Varsinaisen tuomion Hodorkovski sai veronkierrosta ja petoksesta, jonka hän kuitenkin kielsi viimeiseen asti. Monia kirjoja viime aikoina julkaisseen Venäjän turvallisuuspolitiikan ja kansainvälisen rikollisuuden erityisasiantuntijan Mark Galeottin ja Hodorkovskin puheen teemana oli Venäjän rikosoikeudellinen systeemi. Näkökulma ja kysymykset perustuivat $\mathrm{mm}$. Galeottin hiljattaiseen akateemiseen arvostelumenestykseen, The Vory: Russia's super mafia (Yale University Press, 2018), joka ilmestyi maaliskuussa suomeksi nimellä Voima ja Valta: Venäjän mafia Kremlin suojeluksessa. Teos tarkastelee Venäjän hallinnon ja mafian yhteyksiä kuvaten Venäjää kleptokratiaksi, jossa ei erotella toisistaan rikollisuutta ja politiikkaa. Galeotti kuitenkin painotti puheessaan, että kysymys mafian ja hallinnon suhteesta on erittäin monisärmäinen. Sen keskiössä on valtion holhoava ote mafiaan, joka pyrkii tekemään järjestäytyneestä rikollisuudesta turvallisempaa. ${ }^{1}$ Galeotti oli myös lapsiystävällinen konferenssiosallistuja eikä hän välittänyt siitä, että lapseni paineli sormellaan hänen pizzaansa kutsuvierasillallisella. Hodorkovskin kanssa en kokeillut samaa, vaikka konferenssilounas yliopistoruokalassa olisi tarjonnut siihen mahdollisuuden. Itse kykenin seuraamaan Galeottin ja Hodorkovskin keskustelua lapseni kanssa noin neljäkymmentä minuuttia. Tämän jälkeen poika alkoi toistaa lempihokemaansa "hukkapukkapee" sen verran kovaäänisesti, että "hiivimme" pois. 
Venäjän modernin historian vanhempi tutkija Matthias Neumann oli jo käytännössä astunut Pallot'n tilalle konferenssin päävastuuhenkilöksi ja juonsi konferenssin kolmannen pääpaneelin: "Kommunismin kaatumisen todistajat Keski- ja Itä-Euroopassa ja Neuvostoliiton hajoaminen.” Paneelin ideana oli Berliinin muurin murtuminen ja flashbulb memory. Jälkimmäinen viittaa ajankohtiin, jolloin henkilökohtainen ja julkinen muisti yhdistyvät ja ne jaetaan: ihmiset muistavat missä he olivat merkittävien maailmanhistorian tapahtumien aikana ja näin voidaan pohtia yhdessä muun muassa sitä, miten tietyt tapahtumat vaikuttivat ihmisten maailmankuvaan. Neumannin haastateltavana oli kommunismin romahtamista Itä-Euroopassa seurannut Oxfordin yliopiston professori Timothy Garton Ash, joka on lanseerannut termin refolution vallankumouksen ("revolution") asemasta. Termillä hän on kuvannut erityisesti Berliinin muurin murtumisen jälkeistä Puolaa ja Unkaria, jotka hänen mukaansa astuivat vallankumouksen tielle vasta kun uhka Neuvostoliiton sotilaallisesta repressiosta poistui. Ashin kanssa keskustelivat BBC:n palkittu kansainvälinen kirjeenvaihtaja Bridget Kendall sekä itäsaksalainen molekyylibiologi ja esseisti Jens Reich. Reich vaikutti itäsaksalaisen oppositioliikkeen "Neues Forumin" perustamiseen vuonna 1989. Liikkeellä oli vaikutusta Sak-

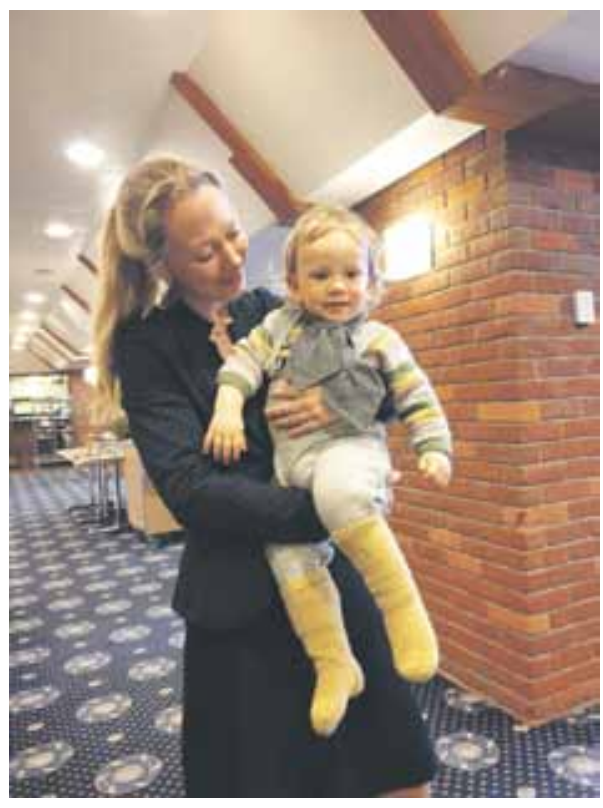

Äiti ja poika aamupalalla Robinson Collegen ruokasalissa Cambridgessa 12.4.2019. Kuvan otti Baseesin puheenjohtaja Matthias Neumann. sojen yhdistymiseen. Baseesin uusi presidentti on myös itse syntynyt Itä-Saksassa. Neumann työskentelee nykyisin Itä-Anglian yliopistossa ja hänen uusin tutkimusprojektinsa tarkastelee kulttuurivaihto-ohjelmia, jotka mahdollistivat amerikkalaisten lasten vierailuja Neuvostoliitossa kylmän sodan aikana.

\section{Tieteidenvälisyyden ja akateemisen vanhemmuuden haasteet}

Konferenssimatka lapsen kanssa oli minulle tietoinen koe ja haaste, jolla testasin nykyisen akateemisen vanhemmuuteni toimivuutta. Astuin tutkimuksellisesti mukavuusalueideni ulkopuolelle. Perestroikan ajan musiikki ja Neuvostoliiton kaatuminen ei ole tutkimukseni keskiössä, mutta siihen tarttuminen toi jälleen uusia perspektiivejä nykyiseen Stalinin ajan kulttuuria käsittelevään tutkimukseeni. Tämän lisäksi koetin olla raskausaikanani haaveilemani ideaali hahmo: rento äiti. Onnistuinko?

Onnistuinhan minä mielestäni suhteellisen hyvin siihen asti, kunnes Standstedin lentokentän pitkät ja perusteelliset turvatarkastukset käynnistyivät. Tässä vaiheessa olin matkustanut junalla Cambridgesta lentokentälle ja luovuttanut matkalaukun ja lastenrattaat lentokoneen ruumaan. Nyt minulla oli enää yli kymmenen kiloa painava lapseni kantorepussa vatsan päällä, selässä minulla oli tietokone, konferenssimateriaalit, vaihtovaatteet, vaipat, tuttipullot ja olalla kannoin ruoat, lelut, liput ja laput. Tällöin päiväkodista saamani ärhäkkä flunssavirus suuttui ja huusi vaativaan sävyyn lentokenttävirkailijoille.

En ole valmis tinkimään hyvästä vanhemmuudesta saati urastani, vaikka lapseni on etusijalla. Minulla pitäisi olla oikeus molempiin. Mikäli menetän työni, se vaikuttaa myös lapseni arkeen. Edessä on vielä monia haasteita, mikäli haluamme tukea etenkin äitien ja yksinhuoltajien oikeutta yhdistää akateeminen ura ja vanhemmuus, sekä pienten lasten oikeutta olla riittävästi vanhempiensa kanssa. Pienen lapsen paikka ei ole konferenssiyleisössä - vaikka se olisi sallittuakin - vaan leikkimässä turvallisen lastenhoitajan holhouksessa. Tällöin konferenssiin osallistuva vanhempikin kykenee keskittymään asiasisältöön, eikä siihen, että lapsi pysyy hiljaisena. Vaikka Suomessa ura ja vanhemmuus yhdistyvät huomattavasti helpommin kuin esimerkiksi Britanniassa saati Yhdysvalloissa, on työssä käyvän vanhemman arki edelleen uuvuttavaa. Kolme viikkoa konferenssin jälkeen tunnen ylpeyttä itsestäni ja pienestä matkakumppanistani, jonka sosiaalisuus teki matkasta sen 
eri käänteissä sulavaa. Mutta olen edelleen fyysisesti hyvin väsynyt.

Entä kuinka kauan täytyy odottaa, että taide ja filosofia ovat jälleen Baseesin kaltaisten konferenssien parrasvaloissa? Tieteidenvälisyys jää monesti historiakonferensseissa ainoastaan kauniiksi sanaksi: yhteiskuntatieteet ja poliittinen historia täyttävät kutsuvierastilan siitäkin huolimatta, että etenkin nykyinen Venäjän historiaa koskeva taiteentutkimus yhdistää sekä yhteiskuntatieteiden että politiikan tutkimuksen menetelmiä. Muun muassa tästä johtuen olin Helsingissä 8. toukokuuta 2019 mukana perustamassa valtakunnallista musiikin ja politiikan tutkimuksen verkostoa.

\section{Elina Viljanen}

\section{Viitteet}

1 Keskustelun voi katsoa internetosoitteessa: https://www.youtube.com/watch?v=ym_jZyHOeDk.

\section{Kattaus venäläistä nykyelokuvaa: Kino Lokakuu 2019}

Kino Lokakuu on Suomi-Venäjä-Seuran, Venäjän tiede- ja kulttuurikeskuksen ja elokuvakulttuuriyhdistys Arkadinin perustama venäläistä nykyelokuvaa ja elokuvantekijöitä esittelevä festivaali, joka järjestettiin ensimmäisen kerran vuonna 2006. Helsingin festivaalin jälkeen elokuvia esitetään usein myös muualla Suomessa. Alkuvuosien taiteellinen johtaja Kari Pirhonen muotoili, että tapahtuma "on aina tunnettu synkistä ja lohduttomista elokuvista, elokuvista ilman valoa ja toivoa”. Ehkä näinkin, mutta ohjelmisto on ollut kautta linjan varsin edustava ja teemoiltaan vaihteleva. Tapahtuma pidettiin alun perin nimensä mukaisesti lokakuussa, mutta siirtyi vuonna 2013 helmikuulle. Kahdestoista Kino Lokakuu Tusovka r.y.:n organisoimine lauantai-illan festivaaliklubeineen järjestettiin 12.-17.2.2019 perinteisesti Eerikinkadun Kino Andorrassa ja juhlatila Dubrovnikissa. Avajaispuheenvuoron piti ohjaaja Markku Lehmuskallio, ja avajaiselokuvana nähtiin Vladimir Kottin ohjaama Venäjän syrjäseudulle sijoittuva groteski komedia Thawed Carp (Karp otmorožennyi, "Sulatettu karppi", 2017), jossa entinen opettaja järjestää omia hautajaisiaan.

Tekijävieraat ovat elokuvien ohella Kino Lokakuun keskeistä antia. Vieraiksi on kutsuttu usein nuoria, vielä tuntemattomia tekijöitä, mutta joukossa on ollut sellaisiakin nimiä kuin Aleksei German (1938-2013), Stanislav Govoruhin (1936 -2018), Aleksandr Mindadze (s. 1949) ja Boris Hlebnikov (s. 1972). Tunnettu dokumenttielokuvaaja ja kouluttaja Marina Razbežkina (s. 1948) on vieraillut Kino Lokakuussa useasti. Tämän vuoden vieraisiin lukeutuivat ohjaajat Mihail Segal (s. 1974) ja Denis Šabajev (s. 1980), joita sain tehtäväkseni haastatella heidän elokuviensa esitysten jälkeen.
Mihail Segal on 45-vuotias ohjaaja, kirjailija, käsikirjoittaja, näyttelijä ja säveltäjä. Hän esitteli Kino Lokakuussa uuden elokuvansa Elephants Can Play Football (Slony mogut igrat v futbol, 2018). Se kertoo nelikymppisestä Dmitristä, jolla on hyvä koulutus, hyvä työ ja turvattu elämä. Hän on edelleen nuorekas, mutta hän on myös yksin. Hänen vanhalla opiskelukaverillaan on aikuinen tytär, mutta Dmitrillä ei ole mitään, vain tyhjää. Ensin hänellä ei ole aavistustakaan, miten ryhtyä tyhjyyttä täyttämään, mutta jokin johdattaa hänet tuon opiskelukaverin tyttären seuraan. Elokuvan nimi on siinä kuultava repliikki. Kyse on valtavasta hotellisängystä, jossa Dmitri ei haluaisi nukkua yllätysvieraakseen saapuneen tytön vieressä. Tyttö toteaa, että tilaa kyllä on, siinä norsut mahtuisivat pelaamaan jalkapalloa. Elokuvaa on pidetty Lolita-aiheisena, mutta siitä ei kuitenkaan ole kyse. Mies ei ole kiinnostunut nuorista tytöistä sukupuolisina olentoina. Ja se on jotenkin riipivää, epänormaalia. Miehen asemaan on vaikea asettua, koska hän haluaa sellaista mikä on toisaalta täysin ymmärrettävää, mutta samalla jotenkin väärin tai outoa. Hän haluaa muokata itselleen toisenlaisen elämän: voi jospa hänelläkin olisi oma aikuinen tytär. Jospa voisi hankkia tyttären samalla tavalla kuin uuden vessanpöntön? Mutta ratkaiseeko se mitään?

Mihail Segal valmistui orjolilaisesta yliopistosta vuonna 1994 ja aloitti elokuva-alan opinnot Moskovan elokuvakoulussa (VGIK), mutta jätti koulun kesken tuottaakseen musiikkivideoita tunnetuille venäläisille muusikoille ja yhtyeille, kuten Bi-2, Splean, Kasta ja Mašina vremeni. Kino Lokakuun yleisölle Segalin aikaisemmatkin elokuvat ovat tuttuja. Franz+Polina (2006) kertoo vuoden 1943 Valko-Venäjälle sijoittuvan SS-sotilaan ja paikallisen naisen rakkaustarinan. 